\title{
Yersinia colitis associated with Crohn's disease
}

\author{
D.F. Treacher* and D.P. Jewell \\ Gastroenterology Unit, Radcliffe Infirmary, Oxford, UK.
}

\begin{abstract}
Summary: A previously healthy patient developed serologically-proven Yersinia pseudotuberculosis enterocolitis and made a complete recovery. Over a year later, further gastrointestinal symptoms developed and Crohn's disease was diagnosed. The possible relevance to the aetiology of Crohn's disease is discussed.
\end{abstract}

\section{Introduction}

There is an extensive literature on the aetiology of Crohn's disease, but the debate continues about whether infective, immunological or inherited factors are involved. This report describes a patient in whom there was clear evidence of an initial Yersinia colitis followed apparently by full recovery, but who has subsequently developed Crohn's disease.

\section{Case report}

A 20 year old woman was admitted to another hospital with a three week history of colicky abdominal pain with diarrhoea, anorexia and weight loss. Examination revealed fever $\left(38^{\circ} \mathrm{C}\right)$ with tenderness in the right iliac fossa. Acute appendicitis was diagnosed and, although an inflamed appendix was removed at operation, inflammation of the terminal ileum and caecum and palpable mesenteric nodes were noted. Postoperatively she remained pyrexial with abdominal pain and developed profuse bloody diarrhoea.

Following transfer on the tenth postoperative day, examination showed she was febrile $\left(38.1^{\circ} \mathrm{C}\right)$, pale, dehydrated and wasted. She had oral candidiasis. The abdomen was generally tender and distended. Sigmoidoscopy showed severe mucosal inflammation only. Investigations revealed a haemoglobin concentration of $6.5 \mathrm{~g} / \mathrm{dl}$, leucocytes $16.8 \times 10^{5} / 1$, erythrocyte sedimentation rate $91 \mathrm{~mm} / \mathrm{h}$, albumin $34 \mathrm{~g} / \mathrm{l}$, potassium $3.0 \mathrm{mmol} / 1$. Blood and stool cultures, salmonella agglutinins and campylobacter titres were repeatedly negative. The test for toxin of Clostridium difficile was negative. Rectal biopsy showed non-specific inflam-

D.F. Treacher, M.R.C.P.; D.P. Jewell, M.A., D.Phil, F.R.C.P.

* Current address: St Thomas' Hospital, London

Correspondence: D.P. Jewell

Accepted: 13 December 1983 mation limited to the mucosa and no granulomata. Plain abdominal X-ray showed dilated small bowel loops. Thickening of the large bowel wall with severe colonic and distal ileal ulceration was diagnosed from the residual barium from a small bowel enema which had been performed immediately prior to transfer. A provisional diagnosis of Crohn's disease was made. The patient was transfused and treated with intravenous fluids, prednisolone and metronidazole. She improved rapidly and was discharged on oral steroids and sulphasalazine.

One month later she was asymptomatic and gaining weight. Yersinia titres taken on admission were now available and revealed a titre for $Y$.pseudotuberculosis type I of 1 in 320 falling to 1 in $\mathbf{4 0}$ four weeks later. Repeat barium studies five months after presentation were normal and the patient had remained asymptomatic on no treatment during that period. A revised diagnosis of yersinia enterocolitis was therefore made.

One year later she developed a posterior anal fissure which responded well to dilatation. Eighteen months after initial presentation, she complained of recent weight loss, lower abdominal pain and distension. At colonoscopy ileo-caecal inflammation and multiple small ulcers were seen. Biopsies from this area and the ascending and transverse colon showed aphthous ulcers, crypt abscesses and transmural inflammation with multinucleate giant cells. Yersinia and campylobacter titres were not raised. A diagnosis of Crohn's disease was made.

\section{Discussion}

Acute colitis caused by Yersinia enterocolitica is well recognized and may take up to one year to resolve (Vantrappen et al., 1977). It is rarely caused by Yersinia pseudotuberculosis (Mair, 1977), although this patient appears to have had a Yersinia 
pseudotuberculosis infection, proven serologically. Subsequently she has developed Crohn's disease. It is not possible to know whether these two events were causally related, occurred coincidentally or indeed whether the Yersinia infection revealed pre-existing but asymptomatic Crohn's disease. To our knowledge, only one other similar case has been described (Payne et al., 1983).

Another possible aetiological factor is the oral

\section{References}

COTTON, P.B. \& LEA THOMAS, M. (1971). Ischaemic colitis and the contraceptive pill. British Medical Journal, 2, 27.

MAIR, N.S. (1977). Yersinia infections. In Topics in Gastroenterology 5, S.C. Truelove \& Emanoel Lee (Eds), p. 325. Blackwell Scientific Publications: Oxford.

PAYNE, M., GIRDWOOD, A.H. \& ROOST, R.W. Yersinia enterocolitica and Crohn's disease: a case report. (Submitted) contraceptive which the patient was taking which may be associated with a segmental colitis (Cotton and Lea Thomas, 1971). In this case, despite continued use of a low-dose oral contraceptive, the patient was largely asymptomatic for eighteen months and a barium $\overline{\vec{B}}$ enema was normal in that period. The presence of a fissure and multinucleate giant cells also make a pillrelated colitis unlikely.

VANTRAPPEN G., AGG, H.O., PONETTE, E., GEBOES, K. \& BERTRAND, P.H. (1977). Yersinia enteritis and enterocolitis: gastroenterological aspects. Gastroenterology, 72, 220. 